\title{
Leishmania guyanensis parasites block the activation of the inflammasome by inhibiting maturation of IL-1 $\beta$
}

\author{
Mary-Anne Hartley ${ }^{1, \text {, }}$, Remzi O. Eren ${ }^{1, \text {, }}$, Matteo Rossi ${ }^{1}$, Florence Prevel ${ }^{1}$, Patrik Castiglioni ${ }^{1}$, Nathalie Isorce ${ }^{1}$, \\ Chantal Desponds ${ }^{1}$, Lon-Fye Lye ${ }^{2}$, Stephen M. Beverley ${ }^{2}$, Stefan K. Drexler ${ }^{1, \&}$, Nicolas Fasel ${ }^{1, \&, *}$ \\ ${ }^{1}$ Department of Biochemistry, University of Lausanne, Epalinges, Switzerland. \\ 2 Department of Molecular Microbiology, Washington University School of Medicine, St. Louis, Missouri, United States of America. \\ "These authors equally contributed to this work. \\ \& These authors also equally contributed to this work. \\ * Corresponding Author: \\ Nicolas Fasel, Department of Biochemistry, University of Lausanne, Chemin des Boveresses 155, Epalinges, Switzerland, $\mathrm{CH}-1066$; \\ Tel: 004121692 5732; E-mail: nicolas.fasel@unil.ch
}

\begin{abstract}
The various symptomatic outcomes of cutaneous leishmaniasis relates to the type and potency of its underlying inflammatory responses. Presence of the cytoplasmic Leishmania RNA virus-1 (LRV1) within Leishmania guyanensis, worsens lesional inflammation and parasite burden, as the viral dsRNA genome acts as a potent innate immunogen stimulating Toll-LikeReceptor-3 (TLR3). Here we investigated other innate pattern recognition receptors capable of reacting to dsRNA and potentially contributing to LRV1mediated inflammatory pathology. We included the cytoplasmic dsRNA sensors, namely, the RIG-like receptors (RLRs) and the inflammasome-dependent and -independent Nod-like-receptors (NLRs). Our study found no role for RLRs or inflammasome-dependent NLRs in the pathology of L. guyanensis infection irrespective of its LRV1-status. Further, neither LRV1-bearing $L$. guyanensis (LgyLRV1+) nor LRV1-negative L. guyanensis (LgyLRV1-) activated the inflammasome in vitro. Interestingly, similarly to $L$. donovani, $L$. guyanensis infection induced the up-regulation of the A20 protein, known to be involved in the evasion of inflammasome activation. Moreover, we observed that LgyLRV1+ promoted the transcription of inflammasome-independent NLRC2 (also called NOD2) and NLRC5. However, only NLRC2 showed some contribution to LRV1-dependent pathology. These data confirmed that the endosomal TLR3 pathway is the dominant route of LRV1-dependent signalling, thus excluding the cytosolic and inflammasome pathways. We postulate that avoidance of the inflammasome pathways is likely an important mechanism of virulence in Leishmania infection irrespective of the LRV1-status.
\end{abstract}

doi: 10.15698/mic2018.03.619

Received originally: 04.10.2017;

in revised form: 05.01.2018,

Accepted 08.01.2018,

Published 14.01.2018.

Keywords: Leishmania, Leishmaniavirus, metastatic leishmaniasis, inflammasome, NOD-like receptors, RIG-like receptors, A2O.
Abbreviations:
ASC-apoptosis-associated speck-like protein containing CARD,
$B M D M$ - bone marrow derived
macrophage,
CARD - caspase activation and
recruitment domain,
$C L$ - cutaneous leishmaniasis,
DAMP - danger-associated
molecular pattern,
$D C$ - dendritic cell,
IFN-interferon,
IL - interleukin,
Lgy-Leishmania guyanensis,
LPS - lipopolysaccharide,
LRV - Leishmania RNA virus,
MAVS - mitochondrial antiviral
signaling protein,
NLR - Nod-like receptor,
PAMP - pathogen-associated
molecular pattern,
$P R R$ - pattern recognition receptor,
$R L R-R I G$-like receptor,
$T L R-T o l l-l i k e$ receptor.

\section{INTRODUCTION}

The human protozoan parasite Leishmania is highly immuno-stimulatory, presenting to the host cell a variety of potent pathogen-associated molecular patterns (PAMPs) that shape the outcome of the inflammatory skin disease known as cutaneous leishmaniasis $(\mathrm{CL})[1]$. CL is a prevalent but neglected tropical disease affecting over 2 million people per year with an expanding geographical reach and a 
diverse clinical presentation. The various symptomatic outcomes of $\mathrm{CL}$ can be categorised by the type and potency of its underlying inflammatory response: ranging from a single, self-healing lesion at the site of inoculation to chronic hyper-inflammatory tissue destruction and the establishment of disfiguring metastatic lesions that are refractory to routine therapies [2]. These inflammatory responses have a high-degree of species-specificity, where metastatic and chronic complications occur mainly in infections of the Leishmania Viannia subgenus found in Central and South America [3] [4].

We previously identified a cytoplasmic dsRNA virus within metastatic L. guyanensis ( $L g y$ ) parasites that acts as a potent innate immunogen capable of worsening lesional inflammation [5] and prolonging infected macrophage survival [6]. The dsRNA genome of Leishmania RNA virus (LRV1) binds to and stimulates endosomal Toll-LikeReceptor-3 (TLR3), inducing destructive hyperinflammation [5] and metastasis in an immunosuppressed environment [7]. Further, the presence of LRV1 in L. guyanensis and $L$. braziliensis negatively affects the patients response to anti-Leishmania drugs, as it is predictive of treatment failure and symptomatic relapses $[8,9]$, and potentially worsens the disease outcome in patients coinfected with HIV [10].

By recognising PAMPs and danger-associated molecular patterns (DAMPs) via innate pattern recognition receptors (PRRs), the mammalian immune system can respond rapidly to infection and tissue damage. These PRRs are able to initiate a wide variety of robust inflammatory pathways tailored to suit the stimulatory ligand. Depending on their ligand specificity, localization and signalling pathway, PRRs are classified into three major families: the TLRs (Toll-like receptors), the RLRs (retinoic acid-inducible gene-l-like receptors) [11] and the NLRs (nucleotide-binding-domain, leucine-rich repeat containing receptors).

RLRs are a small family of RNA helicase enzymes found exclusively in the cytosol that launch an anti-viral response after binding cytosolic RNA [12]. Most active in dendritic cells (DCs), macrophages and fibroblasts, RLRs comprise of two major family members: RIG-I (retinoic acid-inducible gene-I) and MDA-5 (melanoma differentiation-associated protein 5) that are activated by binding cytosolic RNA. RIG-I typically recognizes $5^{\prime}$ triphosphate short uncapped dsRNA and SSRNA, while MDA-5 recognises longer dsRNA strands [13]. Both RIG-I and MDA-5 signal through a common adaptor molecule, MAVS (mitochondrial antiviral signalling protein) to induce a type I interferon (IFN) mediated antiviral response via IRF-3 as well as an NF-KB-type inflammatory response [14]. As RLRs are present in the cytosol, their involvement in LRV1-mediated leishmaniasis would indicate that LRV1 is able to exit the phagolysosome, where the parasite survives, and to reach the host cell cytoplasm.

DAMPs such as intracellular content released from dying cells (e.g. nucleic acids, heat-shock proteins and ATP) or damaged components of the extracellular matrix (e.g. hyaluronic acid) are recognised by NLRs. NLR sensing of DAMPs can result in a potent immune response or an in- flammatory form of cell death, termed pyroptosis. Additionally, several NLRs are able to respond to PAMPs such as bacterial cell wall components and viral RNA. NLR activation can be accomplished in a fashion similar to that of TLRs, where NF-KB or IRFs are mobilised to produce proinflammatory cytokines or type I IFNs, respectively. Alternatively, several NLRs can oligomerise to form a large macromolecular scaffold, called the "inflammasome". Currently, 7 of the 22 human NLR members are known to oligomerise into inflammasomes, namely, NRLB/NLRC4 [15] and NLRP-1, -3, -6, -7, and -12 [16-20]. The inflammasome recruits and activates inflammatory caspases leading to the cleavage and activation of pro-IL-1 $\beta$ and pro-IL-18 [21, 22]. They are formed by the oligomerization of caspase activation and recruitment domains (CARDs), which are either included in the NLR structure such as NLRC4 and NLRP1 or recruited in an ASC (apoptosis-associated speck-like protein containing (ARD) protein, which is the case for the formation of the NLRP3, 6, 7, and 12 inflammasome. Additionally, the non-NLR protein, absent in melanoma 2 (AIM2), which contains pyrin and HIN200 domains, senses dsDNA to form an inflammasome by ASC recruitment [23].

To date, only a few studies have thoroughly explored the role of inflammasomes in leishmaniasis. The clearance of $L$. amazonensis, $L$. infantum and $L$. braziliensis species is correlated to an NLRP3-dependent production of nitric oxide and IFN- $\gamma$ [24]. The authors show that the NLRP3 inflammasome activates IL-1 $\beta$, and that the IL-1 receptor and its MyD88 adaptor protein are necessary and sufficient to trigger parasitotoxic oxidative stress. Different components of the NLRP3 inflammasome were found to be upregulated also in a macrophage system of $L$. major infection [25]. However, oppositely to the observation in L. infantum and L. braziliensis, inflammasome activation worsens the outcome of $L$. major infection, accelerating the course of disease or inducing non-healing lesions [26, 27]. Predictably, the effects of inflammasome activity could differ widely amongst various Leishmania species, ranging from protective in $L$. amazonensis, $L$. infantum and $L$. braziliensis infection [24] to pathogenic in cutaneous species from the Paleotropics $[26,27]$ and contrasting in visceralizing $L$. donovani, where it has been involved in the development of protective immunity [28] but has also recently been correlated with increased visceralization if activated by gut bacteria transmitted during a sand fly bite [29]. Of note, however, IL-1 $\alpha$, IL-1 $\beta$ and IL-18 can be activated independently of the inflammasome [30] and thus these roles are not necessarily indicative of NLR activity. Recently, A20 (also named TNF- $\alpha$-induced protein 3), a deubiquitinating protein, was reported to inhibit NF-KB activation by deubiquitinating TRAF6 and also to block inflammasome activation by inhibiting IL-1 $\beta$ maturation independently of its effect on NF-kB [31]. In L. donovani infection, A20 was shown to inhibit TLR signalling, decreasing the pro-inflammatory response, thus favouring parasite survival [32] by blocking both pro-IL-1 $\beta$ and pro-caspase-1 maturation [33]. 
In this study, we investigated the role of several nonTLR3 pathways of viral dsRNA recognition during LRV1mediated pathology in a murine model of $L g y$ infection. To this end, we performed an expression array of NLR and RLR components in Lgy infection, probing for markers of Lgy induced inflammasome activation at a cellular level. We then tested the role of these components on LRV1dependent leishmanial pathology in a murine model of infection.

\section{RESULTS}

\section{LRV1 does not activate RLR signaling}

MAVS is the common adaptor molecule essential in the signalling of RIG-I and MDA-5 [34]. Therefore, to investigate whether RLRs contributed to LRV1-mediated parasite survival and inflammation, we infected bone marrow derived macrophages (BMDMs) from C57BL/6 (WT) and $\mathrm{MAVS}^{-/-}$mice with LgyLRV1+ or LgyLRV1- parasites. We found that the absence of MAVS did not affect LRV1induced up-regulation of the signature NF- $\kappa B$ cytokines IL6 and TNF- $\alpha$ (Fig $1 \mathrm{~A}$ and 1B). Subsequently, to include the effect of all cells in which RLRs may be activated in the context of the leishmanial lesion, we monitored disease progression in a murine model of infection. Here, mice lacking MAVS signalling did not show any visible variation in lesional swelling (Fig 1C) or parasite burden (Fig 1D), as compared to the WT control. Thus, we could exclude RLRs as sensor molecules participating in an LRV1-dependent exacerbation of the disease and conclude that LRV1 dsRNA does not reach the host cell cytoplasm.
A

\section{IL-6}

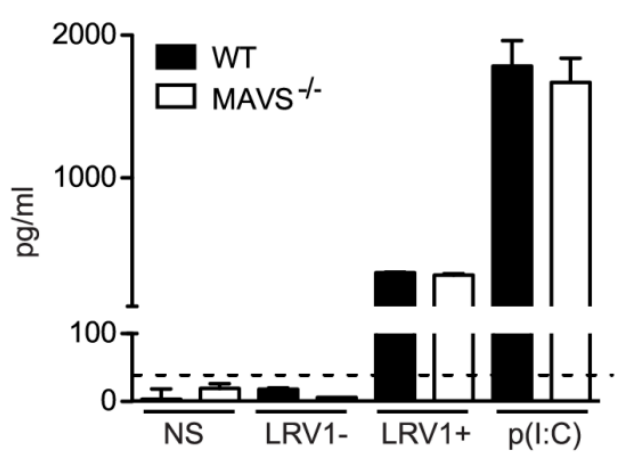

C

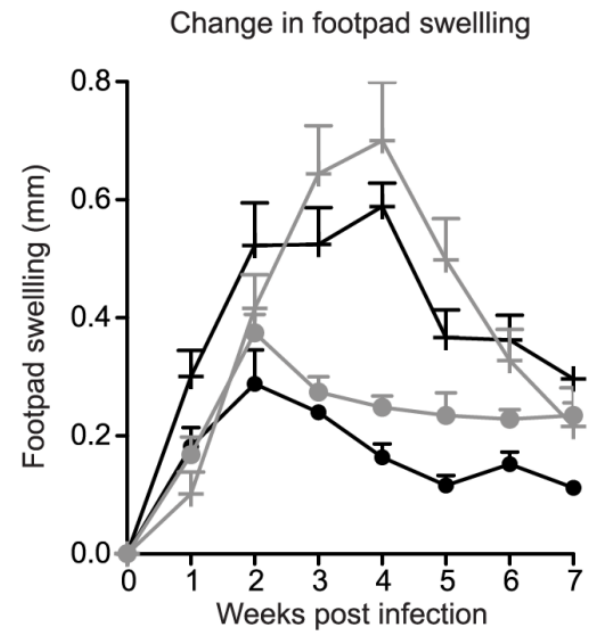

B

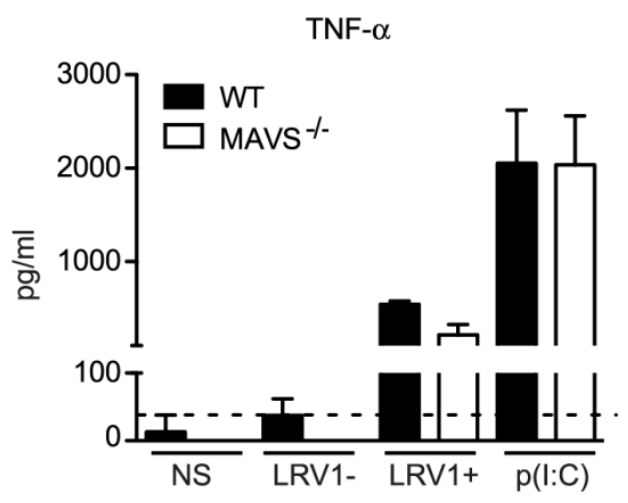

In vivo parasite luminescence

WT

+LRV1+

- LRV1-

MAVS $-/-$

+LRV1+

- LRV1-

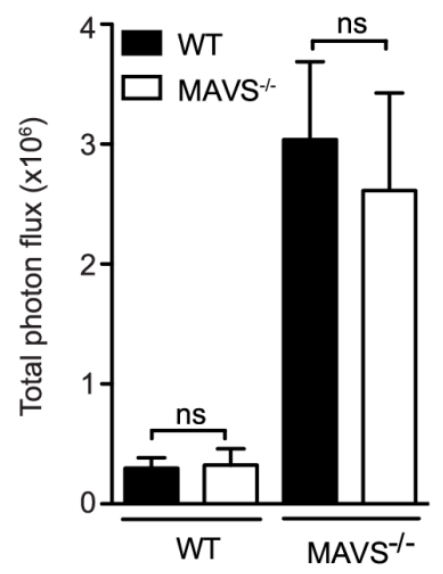

FIGURE 1: LRV1 does not activate RLR signaling. (A, B) BMDMs from mice deficient in MAVS and their C57BL/6 WT counterparts were infected with $L g y L R V 1+$ or $L g y L R V 1$ - parasites or stimulated with a synthetic TLR3 ligand, poly (I:C). After 24 hours, the NF- $K B$ cytokines, IL-6 (A) and TNF- $\alpha$ (B) in BMDM supernatant were quantified by ELISA. (C, D) MAVS ${ }^{-/}$and C57BL/6 WT mice were infected with LgyLRV1+ or LgyLRV1- parasites in their hind footpads. (C) Weekly lesional swelling was monitored as a proxy for disease progression. (D) At the peak of infection (4 weeks), parasite burden was measured by in vivo luminescence, by injecting mice intra-peritoneally with $15 \mathrm{mg} / \mathrm{kg}$ luciferin. Data is representative of a minimum of three independent experiments, using at least five mice per condition, and showed as mean \pm SEM. Significance tested by Student's t-test (bar graphs) or one-way Anova (disease score), ns: non-significant. 
LRV1 promotes the transcription of the inflammasome components, caspase-1, IL-1 $\beta$, NLRP3 and AIM2

To identify the possible interaction between LRV1 and the inflammasome, we performed an expression assay of the key inflammasome signalling transducers as well as the major inflammasome-forming PRR family. We focused on genes encoding the common inflammasome components asc, caspase 1 and il1beta (Fig 2A), and the inflammasomeforming members nIrc4 and naip5 (Fig 2B), the NLRP family members nlrp1, nlrp3, nlrp12 (Fig 2C) and a non-NLR inflammasome-forming molecule aim2 (Fig 2D). BMDMs were infected with LgyLRV1+ or LgyLRV1- parasites, or stimulated with the synthetic TLR3 agonist, poly $(I: C)$, and then prepared for qRT-PCR analysis. We found that TLR3 stimulation was able to potently induce the transcription of genes including caspase-1, IL-1 $\beta, n / r p 3$ and aim2 but not asc, nlrc4, naip5, nlrp1 and nlrp12 (Fig 2). Taken together, these results showed that LRV1 and poly $(I: C)$ mediated TLR3 activation can prime the inflammasome components and promote the transcription of certain NLRs and AIM2.
L. guyanensis does not activate the inflammasome in macrophages, irrespective of its LRV1 status

Based on the transcriptional data, we could expect that LRV1 would activate the inflammasome. Such activation involves the autocatalytic cleavage of pro-caspase 1 into its p20 and p10 subunits. In turn, active caspase-1 cleaves and activates pro-IL-1 $\beta$ and pro-IL-18. Importantly, while pro-IL18 and pro-caspase- 1 are constitutively expressed, the transcription of pro-IL-1 $\beta$ is under the control of NF-KB. Therefore, inflammasome activity requires a "priming" step via NF-KB activation before a second signal activates the inflammasome. NF-KB-dependent TLR3 signalling as observed in dsRNA activation is one such pathway leading to inflammasome priming $[22,35]$.

To investigate whether we were able to activate the inflammasome in our BMDMs, we primed BMDMs with lipopolysaccharide (LPS) for 3 hours before LgyLRV1+ or LgyLRV1- infection, and added nigericin treatment as a positive control of inflammasome activation. Cell lysates and cell culture supernatants were probed for the pro- and cleaved forms of caspase- 1 by immunoblotting (Fig 3A). $L g y L R V 1+$ infection or poly $(\mathrm{I}: \mathrm{C})$ treatment increased the expression of the pro-form of IL-1 $\beta$, and thus acted as pri-

A

asc

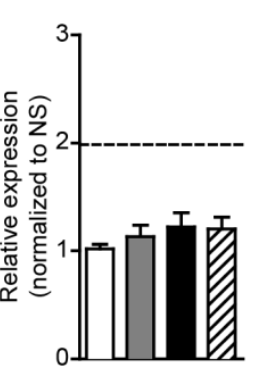

C

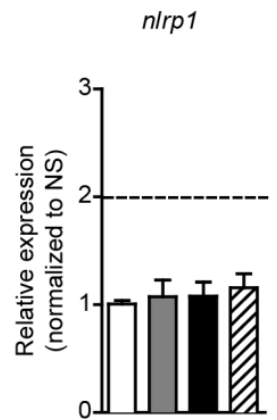

caspase 1

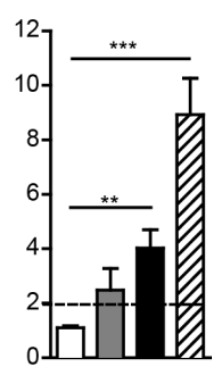

nlrp3

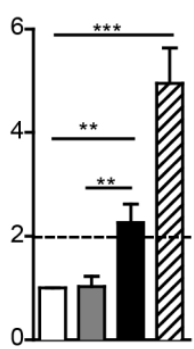

il1beta

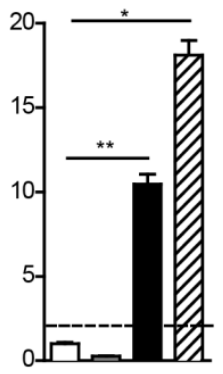

nlrp12
B naip5

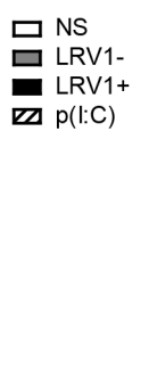

$\mathrm{D}$
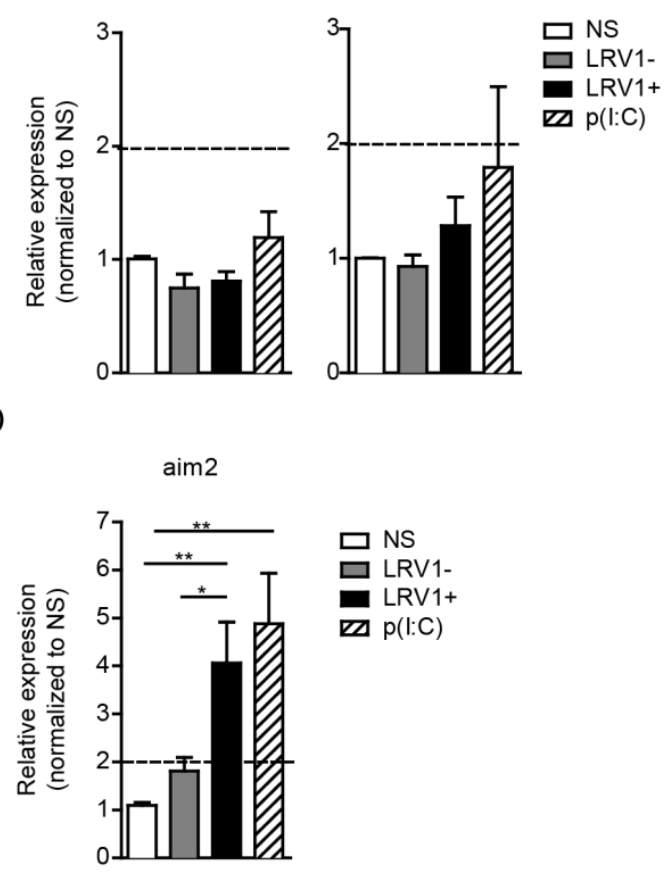

FIGURE 2: LRV1 promotes the transcription of the inflammasome components, caspase-1, IL-1 $\boldsymbol{\beta}, \mathbf{N L R P 3}$ and AIM2. BMDMs from C57BL/6 mice were infected with LgyLRV1+ or LgyLRV1- parasites or stimulated with a synthetic TLR3 ligand, poly(I:C). After 6 hours and 12 hours, mRNA was quantified by qRT-PCR. (A) The common inflammasome components ASC, Caspase-1 and IL-1 13 and the inflammasome-forming members of the (B) NLRC family, (C) NLRP family and (D) a non-NLR inflammasome-forming molecule, AIM2 were measured. Levels are representative of both 6-hour and 12-hour time points. Representative results are shown from at least three independent experiments, using two technical and two biological replicates, and showed as mean \pm SEM. Non-parametric Student's $t$-test is shown. ${ }^{*} p<0.05, * * p<$ $0.01, * * * p<0.001$. A cut off value of 2 -fold was used as a limit of significance and is indicated as a dotted line. 
ming signals. However, L. guyanensis parasites, irrespective of their LRV1 status did not activate the inflammasome in BMDMs, since the IL-1 $\beta$ cytokine and cleaved active caspase- 1 could not be detected in the cell supernatant (Fig $3 \mathrm{~A}$ and $3 \mathrm{~B}$ ). Taken together, we were able to definitively exclude inflammasome activation in the macrophage host cell during infection with L. guyanensis parasites.

The inflammasome does not contribute to disease pathology in a murine model of Lgy infection, irrespective of its LRV1 status

As the macrophage is just one of the many cells with potential inflammasome activity in the skin $[36,37]$, it was important to verify inflammasome activity in the physiological context of an in vivo infection. Using mice deficient in caspase1/11 (thus lacking both the canonical caspase-1dependent and non-canonical caspase-11-dependent pathway of inflammasome activation [38]) or ASC, we found no significant differences in the development of lesional swellings for $L g y$ infection, irrespective of LRV1 presence (Fig 4A and 4B). These mice also did not display any differences in parasite burden at the peak of infection as quantified by in vivo luminescence (Fig 4C and 4D). Moreover, the conditional knockouts of a floxed asc gene using CRE expression in DCs, macrophages or keratinocytes mediated by promoters Itgax (CD11C), lysosome 2 (LysM) and keratin 14 (K14), respectively, did not affect the LRVmediated disease progression in mice, thus allowing us to exclude the contribution of the inflammasome of other cell types such as DCs, neutrophils and keratinocytes that are present in lesions (Fig S1). Consistent with these results, the parasite burden in macrophages deficient in ASC, caspase-1 and IL-1 $\beta$ were similar to WT macrophages 24 hours post infection (Fig 4E). In conclusion, the inflammasome did not have any effect on lesional pathology or parasite burden in Lgy infection irrespective of its LRV1 status.

\section{L. guyanensis induces the expression of the inflam- masome-inhibitor protein A20}

Recently, A20 was further shown to promote $L$. donovani virulence, as it inhibits inflammasome formation possibly by blocking pro-IL-1 $\beta$ and procaspase-1 maturation [33]. Considering that we observed an inhibition of the activation of the inflammasome, we investigated whether LgyLRV1+ or LgyLRV1- could induce the expression of A20. We therefore infected BMDMs with LgyLRV1+ or LgyLRV1and analysed cell lysates for increased expression of $A 20$ by immunoblot at 4 and 8 hours post infection. As a positive control, we infected BMDMs with two strains of $L$. infantum and analysed A20 expression. Similarly to L. infantum, in our model of macrophage infection, LgyLRV1+ and LgyLRV1- induced the expression of A20 (Fig 5A), suggesting its possible involvement in the inhibition of inflammasome activation by blocking IL-1 $\beta$ maturation [31]. To better assess LRV1 involvement in A20 induction, we quantified by densitometric analysis the expression of A20 in $L g y L R V 1+$ or LgyLRV1- infected or poly $(\mathrm{I}: \mathrm{C})$ treated macrophages. Interestingly, at early time points, infection with LgyLRV1+ parasites significantly increased A20 expression compared to both $L g y L R V 1$ - infection or poly $(\mathrm{I}: \mathrm{C})$ treatment, suggesting an additive effect between Leishmania infection and TLR3 stimulation (Fig 5B).
A

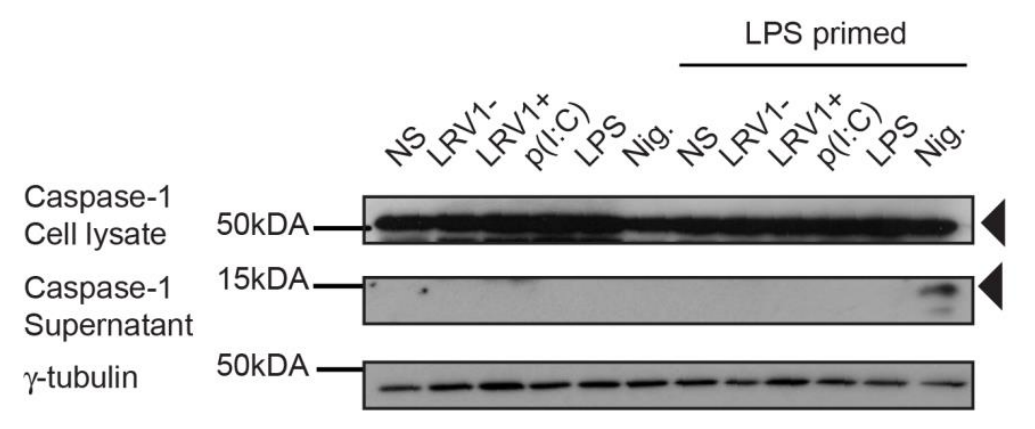

B

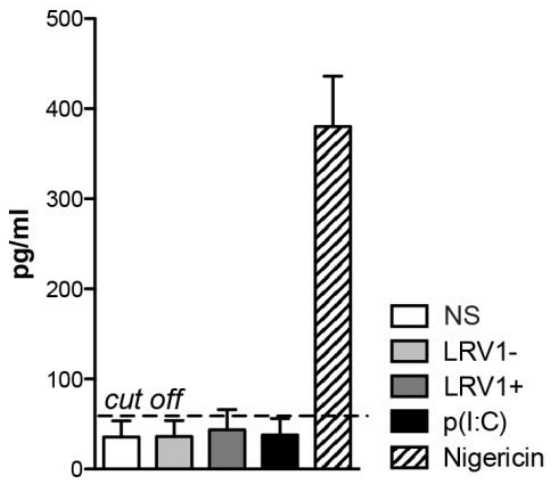

FIGURE 3: L. guyanensis does not activate the inflammasome in macrophages, irrespective of its LRV1 status. (A-B) BMDMs from C57BL/6 WT mice were primed with $200 \mathrm{ng} / \mathrm{ml}$ of LPS for 3 hours. Subsequently, cells were incubated with LgyLRV1+ or LgyLRV1- parasites, poly(I:C) or culture medium. Additionally, a 1 hour treatment with $5 \mu \mathrm{M}$ of Nigericin was used as a positive control for the inflammasome activation. Proteins were extracted from cell lysates (CL) and supernatants (SN). (A) Cell lysates were blotted for caspase-1. (B) IL-1B detected by ELISA in cell-free supernatant. Graphs are representative of a minimum of three independent experiments, using four technical and two biological replicates, and showed as mean \pm SEM. Non-parametric Student's $t$-test was used to calculate significance. 
A

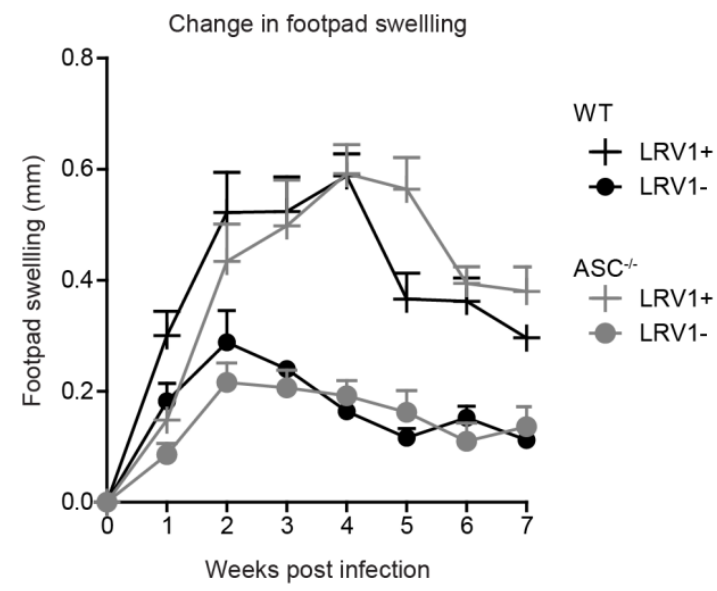

C

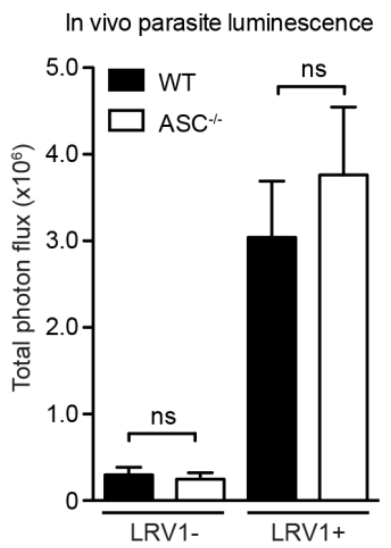

D

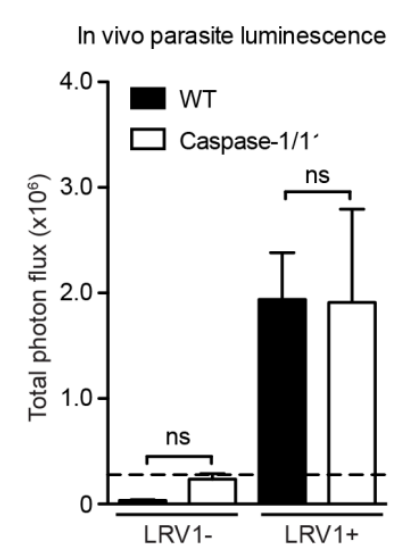

B

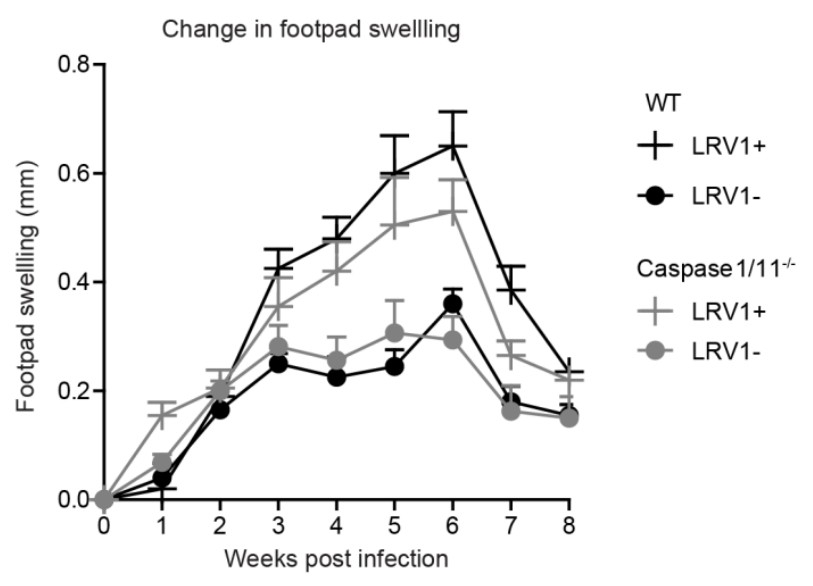

E

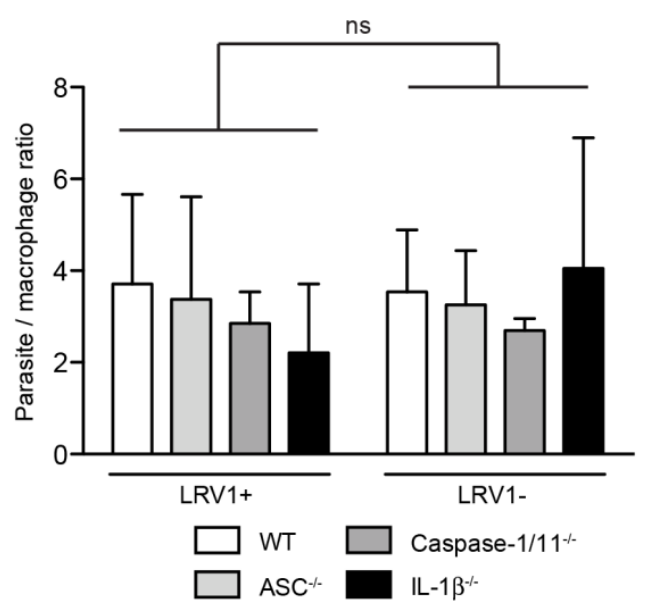

FIGUER 4: The inflammasome does not contribute to disease pathology in a murine model of Lgy infection, irrespective of its LRV1 status. WT, ASC ${ }^{-1-}$ and Caspase1/11 $1^{-1-}$ mice were infected with LgyLRV1+ or LgyLRV1- parasites in their hind footpads. (A, B) Weekly lesional swelling was monitored as a proxy for disease progression. (C, D) At the peak of infection (4 weeks), parasite burden was measured by in vivo luminescence, by injecting mice intra-peritoneally with $15 \mathrm{mg} / \mathrm{kg}$ luciferin. (E) BMDMs derived from C57BL/6 mice deficient in ASC, Caspase-1/11 and IL-1 $\beta$ were infected with either LgyLRV1+ or LgyLRV1- parasites for 24 hours then stained with DAPI and acquired using high-content microscopy. Parasite burden was unbiasedly quantified using computational image analysis. The data shown is representative of a minimum of three independent experiments, using at least 5 mice per condition, and showed as mean \pm SEM. Statistical significance was quantified by performing Student's t-test (bar graphs) or one-way Anova (disease score), ns: non-significant.

LRV1 induces the expression of inflammasomeindependent NLRs: NLRC1, NLRC2 and NLRC5

Many of the inflammasome-independent NLR family members are able to recognise viral components and often use signalling pathways similar to that of the TLR3-LRV1 response. To identify NLRs of interest in our model, we screened BMDMs for LRV1-induced expression of the inflammasome-independent NLR members that are known components of the anti-viral response.

NLRC2 can act as a cytoplasmic PRR for ssRNA, the replicative RNA and mRNA of Totiviridae [39], and signal through MAVS to promote IFN- $\beta$ transcription via IRF3 [40]. However, in macrophages stimulated with poly(I:C) NLRC2 is not implicated in the production of IFN- $\beta$, TNF- $\alpha$ and IL- 6 [40]. Oppositely, it was reported that NLRC1 and NLRC2 are induced in response to viral infection, poly(I:C) or IFN- $\beta$ stimulation and to enhance the production of proinflammatory cytokines [41]. Further, NLRC2 promotes the CCL2-dependent recruitment of inflammatory monocytes [42]. To test for the expression of NLRC1 and NLRC2 in our in vitro infection model, we infected WT BMDMs with LgyLRV1+ or LgyLRV1- parasites, or stimulate them with poly $(\mathrm{I}: C)$. Six hours post infection, BMDMs were lysed and the expression of different NLR transcript was measured by qRT-PCR. In accordance with published data, we observed that both LRV1 and poly $(\mathrm{I}: \mathrm{C})$ stimulation promoted the 
A

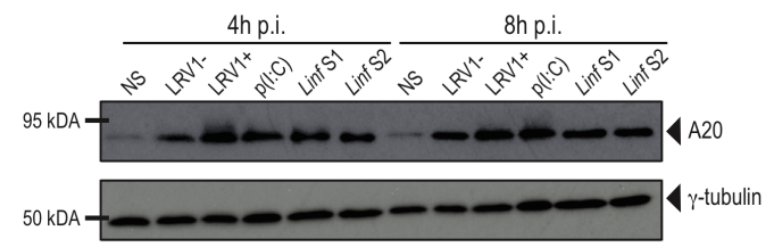

B

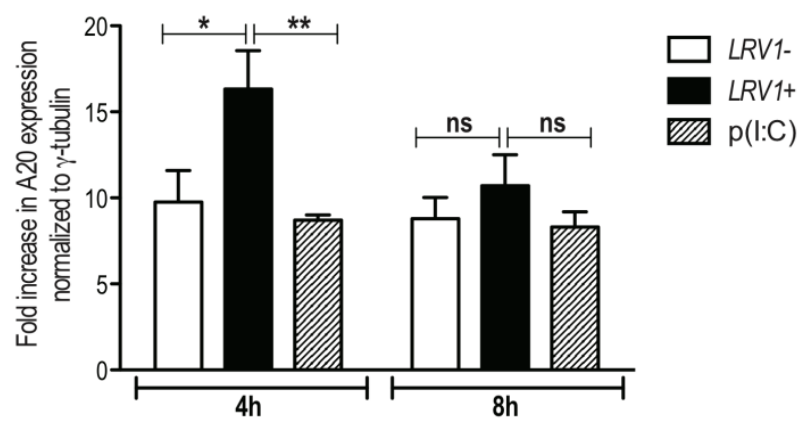

FIGURE 5: L. guyanensis and L. infantum infection induce the up-regulation of the inflammasome inhibitory factor, A20. BMDMs from C57BL/6 WT mice were infected with LgyLRV1+, LgyLRV1-, Linf S1 or Linf S2 parasites or stimulated with poly(I:C) (p(I:C)) as a positive control for TLR3 activation. (A) At 4 or 8 hours after infection, cells were collected, proteins were extracted from cell lysates and were blotted for A20 and $\gamma$-tubulin. (B) Quantification of protein expression of LgyLRV1+ or LgyLRV1-infected or poly(I:C) treated macrophages. The graph is representative of four independent experiments, and shown as mean \pm SD. Two-way ANOVA was used to calculate significance. * $p<0.05$; $* * p<0.01 ;$ ns: non-significant.

transcription of $n / r c 1$ and $n / r c 2$ (Fig 6A). Further, it was reported that NLRX1 [43], NLRC3 [44] and NLRC5 [45, 46] negatively regulate mitochondrial antiviral immune signalling. Here, we observed that the stimulation of macrophages with poly $(\mathrm{I}: \mathrm{C})$ or LgyLRV1+ resulted in the induction of $n / r c 5$ (Fig 6B), whereas the expression of $n / r x 1$ and $n / r c 3$ was unaltered (Fig 6B). Together, these results indicated that LRV1-mediated TLR3 activation can act as a priming signal for certain inflammasome-independent NLRs.

\section{NLRC2 deficiency in mice reduces LRV-mediated pathogenesis \\ To determine whether LRV1-mediated upregulation of NLRC2 or NLRC5 in macrophages plays a pathogenic role in LgyLRV1+ infected mice, we investigated disease progres- sion among mice deficient in NLRC2 or NLRC5 as compared to WT mice. Mice lacking NLRC2, showed significantly re- duced parasite load and lesion swelling (Fig 7A and 7B). Oppositely, no discernible difference was seen between WT and NLRC5 ${ }^{-1}$ mice (Fig 7C and 7D). These results indi- cate that LRV1 promotes the virulence of its microbial host partially through NLRC2 in mice.}

\section{DISCUSSION}

The innate immune response to Leishmania formed within the first hours after parasite inoculation is a determining factor for the outcome of leishmaniasis [1]. We previously revealed that the dsRNA genome of an endosymbiotic virus within virulent Leishmania species is able to act as a potent innate immunogen that worsens the outcome of cutaneous disease [5]. Although we showed the essential role of TLR3, we could not formally exclude the role of other PRRs in leishmaniasis such as the RIG-like receptors (RLRs) and various members of the NOD-like receptors (NLRs).

In this study, we found that macrophage infection with LgyLRV1+ parasites resulted in the transcriptional upregulation of several inflammasome components such as caspase-1, IL-1 $\beta$, NLRP3, and AIM2. These results mirrored those of a preliminary effort to profile the transcription of inflammasome components in a macrophage system of infection [25]. However, we found that $L$. guyanensis infection did not activate the inflammasome, irrespective of its LRV1 status. Notably, an infection in primed macrophages was unable to activate caspase-1 or IL-1 $\beta$ and mice deficient in the key inflammasome components ASC and caspase-1/11 showed no change in their disease phenotype. Further, we found no role for RLR-signalling in response to LRV1, as removing its key signalling adaptor protein MAVS had no effect on cytokine production or parasite burden in vitro, nor did this defect have any impact on disease progression in vivo. As MAVS is also a central or synergising adaptor protein for other non-RLR pathways, the unchanged phenotype in $\mathrm{MAVS}^{-/}$mice also excluded the RLR-independent pathway of virus-induced apoptosis via MAVS-MKK7-JNK2 [47]. The absence of a role for RLR signalling indicated that LRV1 was likely not able to exit the phagolysosome to engage these receptors in the cytoplasm and that LRV1 dsRNA recognition was limited to endosomal TLR3.

NLRs are able to detect both PAMPs and DAMPs, which are present in the destructive inflammatory environment of a typical leishmaniasis lesion. NLRs have so far proven protective in murine leishmaniasis caused by L. amazonensis, L. braziliensis and $L$. infantum. This protection was elicited by an NLRP3-dependent production of nitric oxide (NO) involving IL-1 $\beta$ [24]. Upon incubation with LPS, the resultant active IL-1 $\beta$ induced by NLRP3 signalling carried out this response in an autocrine manner, whereby the IL-1 receptor and its MyD88 adaptor protein were necessary and sufficient to trigger parasitotoxic oxidative stress via inducible nitric oxide synthase (iNOS). It should also be noted, however, that LPS can elicit a non-canonical activation of the inflammasome in the cytosol via caspase 11 and its CARD domain [48]. It is likely that production of IL-1 is not sufficient to control the disease for every Leishmania species, since $L$. major was shown to induce IL-1 $\beta$ in 
A

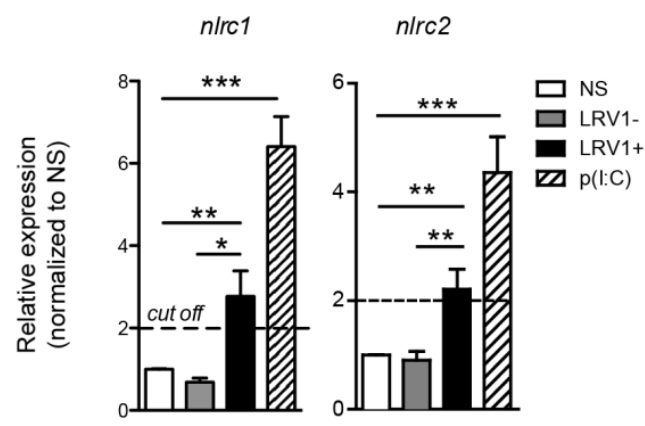

B

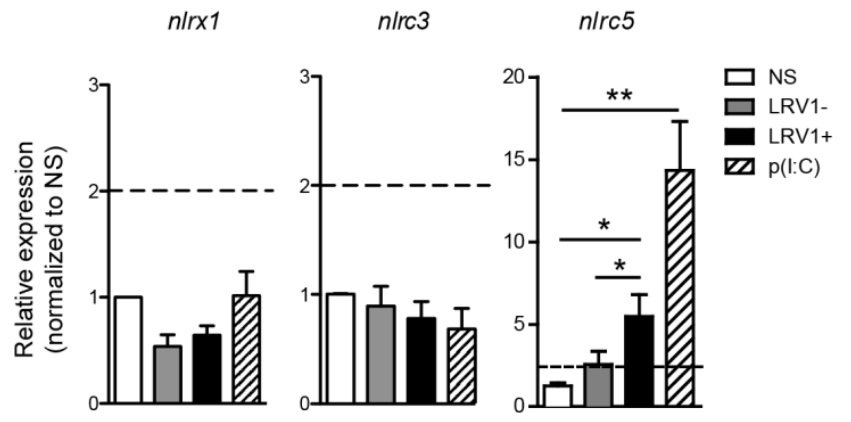

FIGURE 6: LRV1 induces the expression of inflammasome-independent NLRs: NLRC2 and NLRC5. (A-B) BMDMs from C57BL/6 mice were infected with $L g y L R V 1+$ or LgyLRV1- parasites or stimulated with a synthetic TLR3 ligand, poly(I:C). After 6 hours, mRNA was quantified by qRT-PCR for NLRC1 and NLRC2 (A) or for NLRC5, NLRX1 and NLRC3 (B). The bar graphs are representative of at least 3 independent experiments, using 2 technical and 2 biological replicates, and showed as mean \pm SEM. Non-parametric Student's $t$-test was performed. ${ }^{*} p<0.05$, $* * p<0.01, * * * p<0.001$. A cut off value of 2 -fold was shown as a dotted line.

BMDMs when exposed to LPS, but lesion sizes were not increased in caspase-1 deficient mice [24]. Another group showed that blockade of IL-1 $\beta$ signalling rendered BALB/C mice resistant to the infection [27]. Oppositely, NLRP3 inflammasome activation was required to establish nonhealing infection with a particular strain of L. major [26]. Our data showed that, even in the presence of LPS, Lgy parasites did not activate the inflammasome. Therefore, the question of species-specific inflammasome activation and evasion remains to be determined. Of note, Leishmania parasites can be abundantly coated with the leucinerich-repeat (LRR)-enriched surface antigen PSA-2. Interestingly these antigens vary across Leishmania species, and have been associated to increased virulence [49], which could explain the discrepancies in inflammasome activation between different Leishmania species and/or strains. Aside from parasite species, we cannot yet exclude that other factors such as the site of infection (footpad or ear) and the dose of parasites injected, which differ remarkably between reports, could participate in inflammasome activation.

Inflammasome evasion could be an essential virulence strategy in cutaneous leishmaniasis. This evasion could occur via the catalytic activity of GP63, a ubiquitous metalloprotease on the surface of the Leishmania parasite, which can cleave NLRP3 and inflammasome components as shown in vitro but no evidence on the impact of GP63 has been provided to date in vivo [50]. Alternatively, the deubiquitinating enzyme $\mathrm{A} 20$, which is a negative regulator of NF-KB and TLR signalling in L. donovani infection [32] was attributed a new role in suppressing inflammasome activity [31, 33, 51]. We found that, similarly to $L$. donovani, L. guyanensis infection induced A20 expression in macrophages. Interestingly, at 4 hours post infection, A20 expression was higher in LgyLRV1+ infected macrophages, compared to LgyLRV1- or Poly (I:C) stimulation, suggesting an additive role for TLR3 stimulation. It will be interesting to assess whether the same inhibition of inflammasome activation by $\mathrm{A} 20$ is observed in models of Leishmania/virus co-infection where exogenous viral infection exacerbates the severity of $L$. guyanensis infection, promoting parasite dissemination and disease relapses, reproducing the phenotype of $L g y L R V 1+$ infection [52].

The formation of an inflammasome is only one of the many possible signalling pathways of NLRs. Many NLRs respond to viral cues in inflammasome independent pathways. We found that $L g y L R V 1+$ infection, or poly $(I: C)$ treated macrophages, up-regulate the inflammasome independent NLRs: NLRC2 and NLRC5. Moreover, we showed that the infection of mice deficient in NLRC2 but not NLRC5 led to a reduction in parasite burden and lesion size. These results indicated that there could be an NLRC2-mediated host dependent virulence mechanism other than the LRV1mediated inflammatory response. NLRC2 drives the recruitment of monocytes to the site of infection [42]. The LRV1-mediated hyperinflammatory response that promotes parasite survival could require NLRC2-dependent monocyte infiltration, cells which could in turn serve as secondary host cells, thus explaining the reduction of disease severity in $\mathrm{NLRC2}^{--}$mice. This hypothesis will require further investigation.

NLRC5 (CITA) is responsible for MHC-I transcription. The role of MHC-I on CD8 cells in leishmaniasis shows a distinct disease type-specificity as CD8+ T cells are detrimental to mucosal and metastatic infections [53], but protective in simple cutaneous leishmaniasis. The pathogenic role of CD8+ T cells in L. braziliensis infection was shown to be due to tissue-destructive levels of granzyme B [54]. It is thus interesting that NLRC5 deficiency in mice had no effect on disease phenotype in L. guyanensis infection irrespective of LRV1 content, indicating that CD8+ T cells possibly do not play an important role in LRV1-mediated pathology. 
A

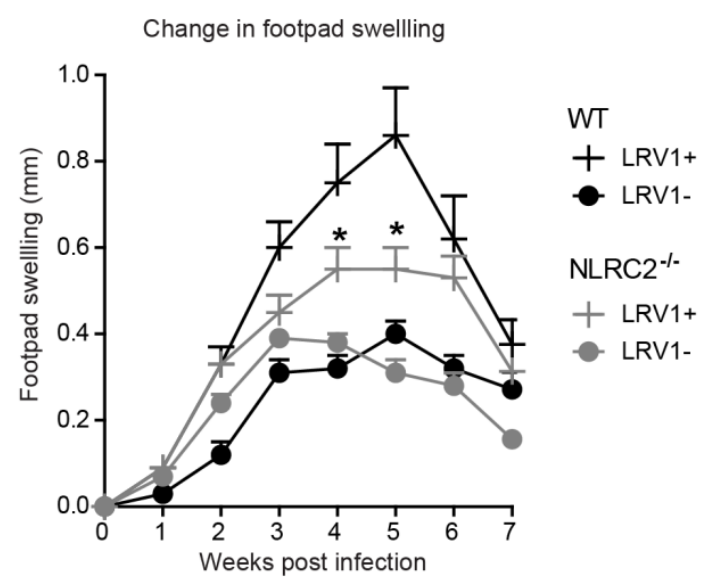

C

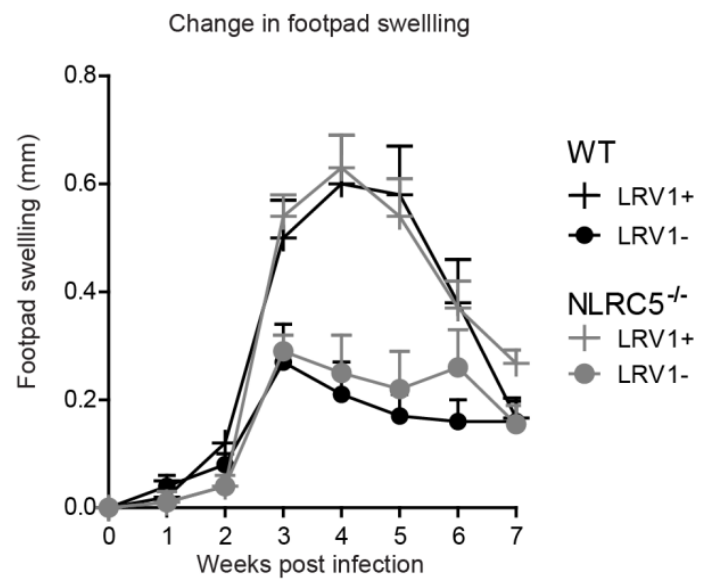

B

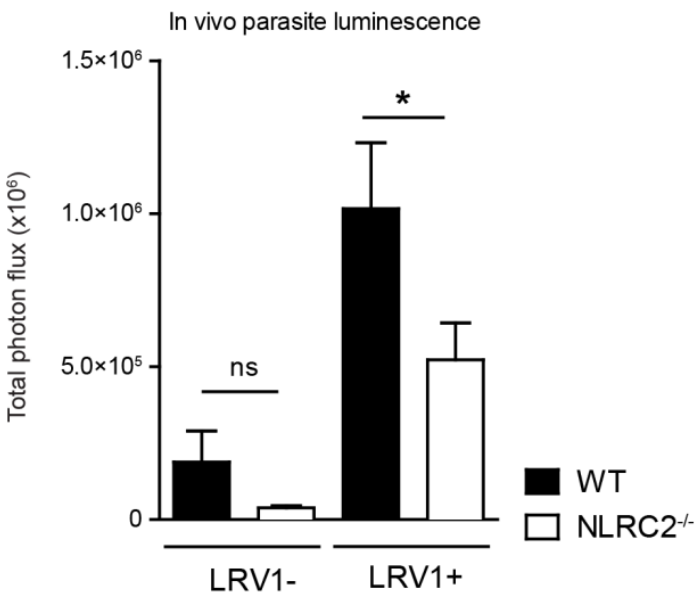

$\mathrm{D}$

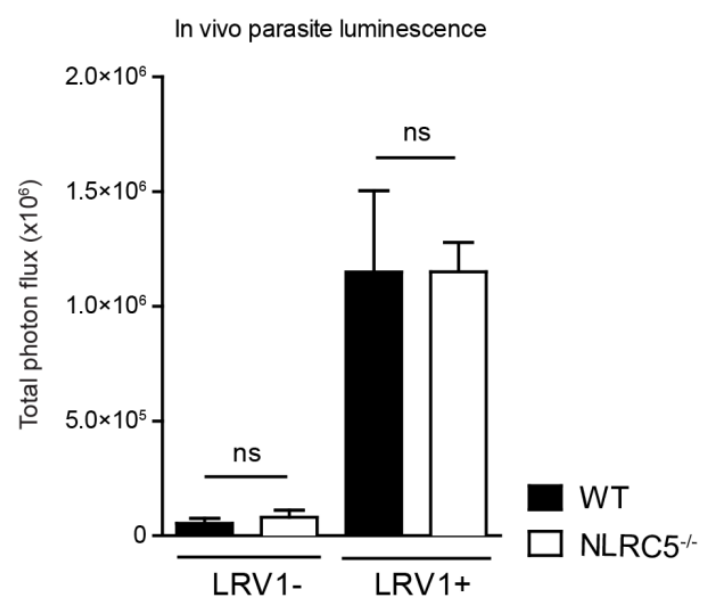

FIGURE 7: NLRC2 reduces LRV-mediated pathogenesis. (A-D) Mice were infected with LgyLRV1+ or LgyLRV1- parasites in their hind footpad. Weekly lesional swelling in infected $\mathrm{NLRC2}^{--}$(A) and $\mathrm{NLC5}^{-1}$ (C) was monitored as a proxy for disease progression. At the peak of infection (4 weeks), parasite burden in infected $\mathrm{NLRC2}^{--}$(B) and $\mathrm{NLRC5}^{-{ }^{-}}$(D) mice was measured by in vivo luminescence, by injecting mice intraperitoneally with $15 \mathrm{mg} / \mathrm{kg}$ luciferin. The representative graph is shown from at least three independent experiments, using two biological replicates in duplicates, and showed as mean \pm SEM. Significance was calculated by Student's $t$-test (bar graphs) or one-way Anova (disease score), ns: non-significant.

Taken together, we were able to show that $L$. guyanensis evades inflammasome activation, where no central components of the inflammasome impacted pathology in a murine model of disease, irrespective of the presence of LRV1. Additionally, we excluded the involvement of RLR receptors in the development of Lgy pathology, and confirmed that LRV1 does not stimulate this cytoplasmic dsRNA receptor. Considering the potently protective role of inflammasome activation previously found in infections by other Leishmania species, these results indicated that inflammasome evasion might be an important mechanism of virulence in Leishmania infection. Finally, as NLR and RLR pathways are the major non-TLR3 routes of dsRNA-induced inflammation, this work confirmed TLR3 as the major pathway of inflammatory pathology in LRV1-mediated cutaneous leishmaniasis.

\section{MATERIALS AND METHODS \\ Ethical Statement}

All animal protocols in this publication were approved by the Swiss Federal Veterinary Office (SFVO), under the authorization numbers VD2113.1 and VD2113.2. Animal handling and experimental procedures were undertaken with strict adherence to ethical guidelines set out by the SFVO and under inspection by the Department of Security and Environment of the State of Vaud, Switzerland. 


\section{In vitro parasite culture}

Two isogenic clones of $L$. guyanensis (MHOM/BR/75/M4147) showing uniformly high levels of LRV1 or completely lacking it were described previously [55]. We refer to these clones as $L g y L R V 1+$ and $L g y L R V 1-$, respectively. Both strains express a firefly luciferase gene (LUC), integrated stably into the locus of the small ribosomal subunit and displayed comparable luminescent efficacy [55]. In addition, two strains of L. infantum were used. The first one was isolated from a dog in Spain (JPC MCAN/ES/98/LLM-722) and will be referred as Linf S1, while the second one was isolated from a human patient in Switzerland (MHOM/CH/2016/BELA) and will be referred as Linf S2. Parasites were cultured in vitro as promastigotes at $26^{\circ} \mathrm{C}$ in freshly prepared Schneider's insect medium (Sigma) supplemented with $10 \%$ heat-inactivated fetal bovine serum (PAA ${ }^{\circledR}$ ), $10 \mathrm{mM}$ HEPES and $50 \mathrm{U} / \mathrm{ml}$ penicillin/streptomycin (Animed ${ }^{\circledR}$ ), $0.6 \mathrm{mg} / \mathrm{L}$ biopterin and $5 \mathrm{mg} / \mathrm{L}$ hemin (Sigma-Aldrich ${ }^{\circledR}$ ). Each passage yielded infectious metacyclic promastigotes after 6 days and stocks were kept no longer than 5 passages.

\section{Murine model of leishmaniasis}

All mice were bred in a specific pathogen-free housing facility at the University of Lausanne, Switzerland and backcrossed at least 10 times onto a C57BL/ 6 genetic background (purchased from Harlan Laboratories, Netherlands). Caspase- $1 / 11^{-1-}$ and $\mathrm{NLRC2}^{-/}$were purchased from Jackson Laboratories (B6.129S2-Casp1tm1Flv/J and B6.129S1-Nod2tm1Flv/J respectively). The following genetic knock-outs were a kind gift from Jürg Tschopp and previously described: $\mathrm{MAVS}^{-1-}, \mathrm{ASC}^{-1 /}, \mathrm{IL}_{-1}-1 \beta^{-1 /}$, and NLRC5-/- [36, 56-58]. Age-matched (6-8 weeks old) female mice were infected in the hind footpads with $3 \times 10^{6}$ stationary phase $L g y L R V 1+$ or $L g y L R V 1$ - promastigotes. Change in footpad swelling was measured weekly using a Vernier caliper as a proxy for disease score.

\section{Parasite quantification by luminescence}

At the peak of infection (week 4/5) parasite burden was quantified using in vivo imaging able to detect luminescence emitted by luciferase-transfected parasites. Briefly, mice were injected intra-peritoneally with D-Luciferin sodium salt (Regis technologies ${ }^{\circledast}$ ) prepared in PBS at a final concentration of $15 \mathrm{mg} / \mathrm{kg}$. After a 10min incubation, mice were anesthetized by continuous gas anesthesia and imaged using a Xenogen Lumina II imaging system (IVIS ${ }^{\circledR}, 10 \mathrm{~min}$ exposure time). Total photon flux over the leishmanial lesions in the footpads was assessed using the associated software (Living Image ${ }^{\circledR}$ ).

\section{BMDM culture, infection and stimulation}

Bone marrow cells were extracted from naive C57BL/6 mice. Erythrocytes were removed by lysis using ACK lysis buffer $\left(1,5 \mathrm{M} \mathrm{NH} \mathrm{Cl}_{4}, 100 \mathrm{mM} \mathrm{KHCO}_{3}, 10 \mathrm{mM}\right.$ EDTA-2Na) and then incubated with macrophage differentiation medium (complete DMEM supplemented with L929-conditioned media) at $37^{\circ} \mathrm{C}$. After 6 days of differentiation, adherent BMDMs were isolated and plated at $1 \times 10^{6} / \mathrm{ml}$ in 48 well plates before being stimulated. Inflammasome activity assays used a pre-stimulation step with $200 \mathrm{ng} / \mathrm{ml}$ LPS (Sigma-Aldrich ${ }^{\circledR}$ ) for 3 hours. Cells were then washed and infected (1:10) with stationary phase $L g y L R V 1+$ or LgyLRV1- parasites or stimulated with the synthetic TLR3 ligand, poly $(\mathrm{I}: \mathrm{C})\left(2 \mu \mathrm{g} / \mathrm{ml}\right.$, Sigma-Aldrich $\left.{ }^{\circledR}\right)$ for 24 hours at $37^{\circ} \mathrm{C}$. A positive control was treated with $5 \mu \mathrm{M}$ nigericin (Sigma-Aldrich ${ }^{\circledR}$ ) for 1 hour, while a negative control was left unstimulated after LPS pre-treatment. Alternatively, for A20 measurement, BMDMs were infected $(1: 10)$ with stationary phase $L g y L R V 1+, \operatorname{Lg} L R V 1-$, Linf S1 or Linf S2 parasites or stimulated with poly(l:C) for 4 or 8 hours at $37^{\circ} \mathrm{C}$.

\section{Western blot}

BMDMs were lysed with a mixture of RIPA Buffer IV (Biotech RB4448), and a Protease/Phosphatase inhibitor cocktail (Cell Signaling 5872S) in PBS. Laemmli's Sample Buffer was added before lysates were size-fractionated by SDS-PAGE and wettransferred to a nitrocellulose membrane. Western Blotting was performed using the following antibodies: rabbit polyclonal anti-mouse caspase-1 p10 (Santa Cruz, SC514), goat polyclonal anti-mouse IL-1 $\beta$ (R\&D Systems, AF-401-NA), rabbit anti-mouse A20 (Cell Signaling, D13H3), mouse monoclonal anti-mouse $\gamma$-tubulin (Sigma-Aldrich ${ }^{\circledR}$ T6557), goat anti-rabbit IgG HRP conjugated (Promega W4011) and goat anti-mouse IgG HRP conjugated (Promega W4021). Where indicated, protein expression was quantified with densitometric analysis using ImageJ software.

\section{High Content Microscopy}

BMDMs were counted with Vi-Cell ${ }^{\circledR}$ (Beckman Coulter). Then, $0.1 \times 10^{6}$ BMMs were seeded on Falcon ${ }^{\circledast} 96$ Well clear-bottom Tissue-Culture treated plate. Cells were infected with stationary phase LgyLRV1+ or LgyLRV1- parasites (1:10) for 24 hours and then fixed with freshly made 3.7\% PFA in PBS. Cells were subsequently stained with DAPI to visualize the nuclei of parasites and macrophages and washed in PBS using a Biotek MultioFlo FX plate washer. 49 ( $7 \times 7$ square) images from each well with $\mathrm{x} 40$ lens were acquired using ImageXpress Micro XLS and analyzed using MetaExpress software.

\section{Statistical analysis}

Statistical significance was determined using an unpaired parametric $t$-test (for single-point analysis on bar-graphs) or a one-way Anova ( $\mathrm{x} / \mathrm{y}$ disease curves) as calculated by GraphPad $^{\circledR}$ software (Prism ${ }^{\text {TM }}$ v5a). Significance was recognized when $p \leq 0.05$ and represented in three ranks namely *: $p \leq 0.05, * *: p \leq 0.01$ and $* * *: p \leq 0.001$.

\section{ACKNOWLEDGEMENTS}

Firstly, the authors are indebted to the veterinary and animal care-taking staff at the University of Lausanne (especially Aubry Tardivel) for ensuring the highest possible ethical standards for animal experimentation. High-content microscopy was performed at the NCCR facility in Geneva through the kind donation of time and expertise by Cansel Ustunel Eren and Dimitri Moreau. Additionally, we thank Dr. Greta Guarda for providing the NLRC5-/- murine model and Dr. Laurent Parmentier for providing $L$. infantum parasites. This work was funded by the Swiss National fund for research (FNRS 310030-153204 and IZRJZ3_164176), the Institute for Rheumatology Research (iRR) and the Pierre Mercier Foundation. SMB and LFL were supported by the National Institutes of Health (RO1Al029646 and R56Al099364).

\section{SUPPLEMENTAL MATERIAL}

All supplemental data for this article are available online at www.microbialcell.com. 


\section{CONFLICT OF INTEREST}

The authors declare no conflict of interest.

\section{COPYRIGHT}

(C) 2018 Hartley et al. This is an open-access article released under the terms of the Creative Commons Attribution (CC BY) license, which allows the unrestricted use, distribution, and reproduction in any medium, provided the original author and source are acknowledged.

\section{REFERENCES}

1. Liu D, Uzonna JE (2012). The early interaction of Leishmania with macrophages and dendritic cells and its influence on the host immune response. Front Cell Infect Microbiol 2: 83. doi: 10.3389/fcimb.2012.00083

2. World Health Organization (2010). Control of the leishmaniases. World Health Organ Tech Rep Ser 949. PMID: 21485694

3. Goto H, Lauletta Lindoso JA (2012). Cutaneous and mucocutaneous leishmaniasis. Infect Dis Clin North Am 26(2): 293-307. doi: 10.1016/j.idc.2012.03.001

4. Alvar J, Velez ID, Bern C, Herrero M, Desjeux P, Cano J, Jannin J, den Boer M, Team WHOLC (2012). Leishmaniasis worldwide and global estimates of its incidence. PLoS One 7(5): e35671. doi: 10.1371/journal.pone.0035671

5. Ives A, Ronet C, Prevel F, Ruzzante G, Fuertes-Marraco S, Schutz F, Zangger $\mathrm{H}$, Revaz-Breton M, Lye LF, Hickerson SM, Beverley SM, AchaOrbea H, Launois P, Fasel N, Masina S (2011). Leishmania RNA virus controls the severity of mucocutaneous leishmaniasis. Science 331(6018): 775-778. doi: 10.1126/science.1199326

6. Eren RO, Reverte M, Rossi M, Hartley MA, Castiglioni P, Prevel F, Martin R, Desponds C, Lye LF, Drexler SK, Reith W, Beverley SM, Ronet $C$, Fasel N (2016). Mammalian Innate Immune Response to a Leishmania-Resident RNA Virus Increases Macrophage Survival to Promote Parasite Persistence. Cell Host Microbe 20(3): 318-328. doi: 10.1016/j.chom.2016.08.001

7. Hartley MA, Bourreau E, Rossi M, Castiglioni P, Eren RO, Prevel F, Couppie P, Hickerson SM, Launois P, Beverley SM, Ronet C, Fasel N (2016). Leishmaniavirus-Dependent Metastatic Leishmaniasis Is Prevented by Blocking IL-17A. PLoS Pathog 12(9): e1005852. doi: 10.1371/journal.ppat.1005852

8. Adaui V, Lye LF, Akopyants NS, Zimic M, Llanos-Cuentas A, Garcia L, Maes I, De Doncker S, Dobson DE, Arevalo J, Dujardin JC, Beverley SM (2016). Association of the Endobiont Double-Stranded RNA Virus LRV1 With Treatment Failure for Human Leishmaniasis Caused by Leishmania braziliensis in Peru and Bolivia. J Infect Dis 213(1): 112-121. doi: 10.1093/infdis/jiv354

9. Bourreau E, Ginouves M, Prevot G, Hartley MA, Gangneux JP, Robert-Gangneux F, Dufour J, Sainte-Marie D, Bertolotti A, Pratlong F, Martin R, Schutz F, Couppie P, Fasel N, Ronet C (2016). Presence of Leishmania RNA Virus 1 in Leishmania guyanensis Increases the Risk of First-Line Treatment Failure and Symptomatic Relapse. J Infect Dis 213(1): 105-111. doi: 10.1093/infdis/jiv355

10. Parmentier L, Cusini A, Muller N, Zangger H, Hartley MA, Desponds C, Castiglioni P, Dubach P, Ronet C, Beverley SM, Fasel N (2016). Severe Cutaneous Leishmaniasis in a Human Immunodeficiency Virus Patient Coinfected with Leishmania braziliensis and Its Endosymbiotic Virus. Am J Trop Med Hyg 94(4): 840-843. doi: 10.4269/ajtmh.150803
Please cite this article as: Mary-Anne Hartley, Remzi O. Eren, Matteo Rossi, Florence Prevel, Patrik Castiglioni, Nathalie Isorce, Chantal Desponds, Lon-Fye Lye, Stephen M. Beverley, Stefan K. Drexler, Nicolas Fasel (2018). Leishmania guyanensis parasites block the activation of the inflammasome by inhibiting maturation of IL-1ß. Microbial Cell 5(3): 137-149. doi: 10.15698/mic2018.03.619

11. Mogensen TH (2009). Pathogen recognition and inflammatory signaling in innate immune defenses. Clin Microbiol Rev 22(2): 240273, doi: 10.1128/CMR.00046-08

12. Schlee M (2013). Master sensors of pathogenic RNA - RIG-I like receptors. Immunobiology 218(11): 1322-1335. doi 10.1016/j.imbio.2013.06.007

13. Kato H, Takeuchi O, Mikamo-Satoh E, Hirai R, Kawai T, Matsushita K, Hiiragi A, Dermody TS, Fujita T, Akira S (2008). Length-dependent recognition of double-stranded ribonucleic acids by retinoic acidinducible gene-I and melanoma differentiation-associated gene 5. J Exp Med 205(7): 1601-1610. doi: 10.1084/jem.20080091

14. Kawai T, Takahashi K, Sato S, Coban C, Kumar H, Kato H, Ishii KJ, Takeuchi O, Akira S (2005). IPS-1, an adaptor triggering RIG-I- and Mda5-mediated type I interferon induction. Nat Immunol 6(10): 981988. doi: 10.1038/ni1243

15. Zhao Y, Yang J, Shi J, Gong YN, Lu Q, Xu H, Liu L, Shao F (2011). The NLRC4 inflammasome receptors for bacterial flagellin and type III secretion apparatus. Nature 477(7366): 596-600. doi: $10.1038 /$ nature 10510

16. Martinon F, Burns K, Tschopp J (2002). The inflammasome: a molecular platform triggering activation of inflammatory caspases and processing of prolL-beta. Mol Cell 10(2): 417-426. PMID: 12191486

17. Martinon F, Petrilli V, Mayor A, Tardivel A, Tschopp J (2006). Goutassociated uric acid crystals activate the NALP3 inflammasome. Nature 440(7081): 237-241. doi: 10.1038/nature04516

18. Wlodarska M, Thaiss CA, Nowarski R, Henao-Mejia J, Zhang JP, Brown EM, Frankel G, Levy M, Katz MN, Philbrick WM, Elinav E, Finlay $B B$, Flavell RA (2014). NLRP6 inflammasome orchestrates the colonic host-microbial interface by regulating goblet cell mucus secretion. Cell 156(5): 1045-1059. doi: 10.1016/j.cell.2014.01.026

19. Khare S, Dorfleutner A, Bryan NB, Yun C, Radian AD, de Almeida L, Rojanasakul Y, Stehlik C (2012). An NLRP7-containing inflammasome mediates recognition of microbial lipopeptides in human macrophages. Immunity 36(3): 464-476. doi: 10.1016/j.immuni.2012.02.001

20. Vladimer GI, Weng D, Paquette SW, Vanaja SK, Rathinam VA, Aune $\mathrm{MH}$, Conlon JE, Burbage JJ, Proulx MK, Liu Q, Reed G, Mecsas JC, Iwakura Y, Bertin J, Goguen JD, Fitzgerald KA, Lien E (2012). The NLRP12 inflammasome recognizes Yersinia pestis. Immunity 37(1): 96107. doi: 10.1016/j.immuni.2012.07.006

21. Gross O, Thomas CJ, Guarda G, Tschopp J (2011). The inflammasome: an integrated view. Immunol Rev 243(1): 136-151. doi: 10.1111/j.1600-065X.2011.01046.x

22. Latz E, Xiao TS, Stutz A (2013). Activation and regulation of the inflammasomes. Nat Rev Immunol 13(6): 397-411. doi: $10.1038 /$ nri3452 
23. Henao-Mejia J, Elinav E, Thaiss CA, Flavell RA (2014). Inflammasomes and metabolic disease. Annu Rev Physiol 76: 57-78. doi: 10.1146/annurev-physiol-021113-170324

24. Lima-Junior DS, Costa DL, Carregaro V, Cunha LD, Silva AL, Mineo TW, Gutierrez FR, Bellio M, Bortoluci KR, Flavell RA, Bozza MT, Silva JS, Zamboni DS (2013). Inflammasome-derived IL-1beta production induces nitric oxide-mediated resistance to Leishmania. Nat Med 19(7): 909-915. doi: 10.1038/nm.3221

25. Mahmoudian Sani M, Hajizade A, Sankian M, Fata A, Mellat M, Hassanpour K, Farnoosh G (2013). Evaluation of the expression of the inflammasome pathway related components in Leishmania major infected murine macrophages. . Eur J Exp Biol 3: 104-109.

26. Charmoy M, Hurrell BP, Romano A, Lee SH, Ribeiro-Gomes F, Riteau N, Mayer-Barber K, Tacchini-Cottier F, Sacks DL (2016). The Nlrp3 inflammasome, IL-1beta, and neutrophil recruitment are required for susceptibility to a nonhealing strain of Leishmania major in C57BL/6 mice. Eur J Immunol 46(4): 897-911. doi: 10.1002/eji.201546015

27. Voronov E, Dotan S, Gayvoronsky L, White RM, Cohen I, Krelin Y, Benchetrit F, Elkabets M, Huszar M, El-On J, Apte RN (2010). IL-1induced inflammation promotes development of leishmaniasis in susceptible BALB/C mice. Int Immunol 22(4): 245-257. doi: 10.1093/intimm/dxq006

28. Mullen AB, Lawrence CE, McFarlane E, Wei XQ, Carter KC (2006). Endogenous interleukin-18 is involved in immunity to Leishmania donovani but its absence does not adversely influence the therapeutic activity of sodium stibogluconate. Immunology 119(3): 348-354. doi: 10.1111/j.1365-2567.2006.02438.x

29. Dey R, Joshi AB, Oliveira F, Pereira L, Guimaraes-Costa AB, Serafim TD, de Castro W, Coutinho-Abreu IV, Bhattacharya P, Townsend S, Aslan H, Perkins A, Karmakar S, Ismail N, Karetnick M, Meneses C Duncan R, Nakhasi HL, Valenzuela JG, Kamhawi S (2017). Gut Microbes Egested during Bites of Infected Sand Flies Augment Severity of Leishmaniasis via Inflammasome-Derived IL-1beta. Cell Host Microbe. doi: 10.1016/j.chom.2017.12.002

30. Netea MG, Simon A, van de Veerdonk F, Kullberg BJ, Van der Meer JW, Joosten LA (2010). IL-1beta processing in host defense: beyond the inflammasomes. PLoS Pathog 6(2): e1000661. doi: 10.1371/journal.ppat.1000661

31. Duong BH, Onizawa $M$, Oses-Prieto JA, Advincula R, Burlingame A, Malynn BA, Ma A (2015). A20 restricts ubiquitination of prointerleukin-1beta protein complexes and suppresses NLRP3 inflammasome activity. Immunity 42(1): 55-67. doi: 10.1016/j.immuni.2014.12.031

32. Srivastav S, Kar S, Chande AG, Mukhopadhyaya R, Das PK (2012). Leishmania donovani exploits host deubiquitinating enzyme A20, a negative regulator of TLR signaling, to subvert host immune response. J Immunol 189(2): 924-934. doi: 10.4049/jimmunol.1102845

33. Gupta AK, Ghosh K, Palit S, Barua J, Das PK, Ukil A (2017). Leishmania donovani inhibits inflammasome-dependent macrophage activation by exploiting the negative regulatory proteins A20 and UCP2. FASEB J. doi: 10.1096/fj.201700407R

34. Hou F, Sun L, Zheng H, Skaug B, Jiang QX, Chen ZJ (2011). MAVS forms functional prion-like aggregates to activate and propagate antiviral innate immune response. Cell 146(3): 448-461. doi: 10.1016/j.cell.2011.06.041

35. Wen H, Miao EA, Ting JP (2013). Mechanisms of NOD-like receptor-associated inflammasome activation. Immunity 39(3): 432-441. doi: 10.1016/j.immuni.2013.08.037

36. Drexler SK, Bonsignore L, Masin M, Tardivel A, Jackstadt R, Hermeking H, Schneider P, Gross O, Tschopp J, Yazdi AS (2012). Tissue- specific opposing functions of the inflammasome adaptor ASC in the regulation of epithelial skin carcinogenesis. Proc Natl Acad Sci U S A 109(45): 18384-18389. doi: 10.1073/pnas.1209171109

37. Gross O (2012). Measuring the inflammasome. Methods Mol Biol 844: 199-222. doi: 10.1007/978-1-61779-527-5_15

38. Kayagaki N, Warming S, Lamkanfi M, Vande Walle L, Louie S, Dong J, Newton K, Qu Y, Liu J, Heldens S, Zhang J, Lee WP, Roose-Girma M, Dixit VM (2011). Non-canonical inflammasome activation targets caspase-11. Nature 479(7371): 117-121. doi: 10.1038/nature10558

39. Wickner RB (1996). Double-stranded RNA viruses of Saccharomyces cerevisiae. Microbiol Rev 60(1): 250-265. PMID: 8852903

40. Sabbah A, Chang TH, Harnack R, Frohlich V, Tominaga K, Dube PH, Xiang $Y$, Bose $S$ (2009). Activation of innate immune antiviral responses by Nod2. Nat Immunol 10(10): 1073-1080. doi: 10.1038/ni.1782

41. Kim YG, Park JH, Reimer T, Baker DP, Kawai T, Kumar H, Akira S, Wobus C, Nunez G (2011). Viral infection augments Nod1/2 signaling to potentiate lethality associated with secondary bacterial infections. Cell Host Microbe 9(6): 496-507. doi: 10.1016/j.chom.2011.05.006

42. Kim YG, Kamada N, Shaw MH, Warner N, Chen GY, Franchi L, Nunez $G$ (2011). The Nod2 sensor promotes intestinal pathogen eradication via the chemokine CCL2-dependent recruitment of inflammatory monocytes. Immunity 34(5): 769-780. doi 10.1016/j.immuni.2011.04.013

43. Moore CB, Bergstralh DT, Duncan JA, Lei Y, Morrison TE, Zimmermann AG, Accavitti-Loper MA, Madden VJ, Sun L, Ye Z, Lich JD, Heise MT, Chen Z, Ting JP (2008). NLRX1 is a regulator of mitochondria antiviral immunity. Nature 451(7178): 573-577. doi: $10.1038 /$ nature06501

44. Zhang L, Mo J, Swanson KV, Wen H, Petrucelli A, Gregory SM, Zhang Z, Schneider $M$, Jiang $Y$, Fitzgerald KA, Ouyang $S$, Liu ZJ, Damania B, Shu HB, Duncan JA, Ting JP (2014). NLRC3, a member of the NLR family of proteins, is a negative regulator of innate immune signaling induced by the DNA sensor STING. Immunity 40(3): 329-341. doi: 10.1016/j.immuni.2014.01.010

45. Benko S, Magalhaes JG, Philpott DJ, Girardin SE (2010). NLRC5 limits the activation of inflammatory pathways. J Immunol 185(3): 1681-1691. doi: 10.4049/jimmunol.0903900

46. Cui J, Zhu L, Xia X, Wang HY, Legras X, Hong J, Ji J, Shen P, Zheng S, Chen ZJ, Wang RF (2010). NLRC5 negatively regulates the NF-kappaB and type I interferon signaling pathways. Cell 141(3): 483-496. doi: 10.1016/j.cell.2010.03.040

47. Huang Y, Liu H, Li S, Tang Y, Wei B, Yu H, Wang C (2014). MAVSMKK7-JNK2 defines a novel apoptotic signaling pathway during viral infection. PLoS Pathog 10(3): e1004020. doi: 10.1371/journal.ppat.1004020

48. Kayagaki N, Wong MT, Stowe IB, Ramani SR, Gonzalez LC, AkashiTakamura S, Miyake K, Zhang J, Lee WP, Muszynski A, Forsberg LS, Carlson RW, Dixit VM (2013). Noncanonical inflammasome activation by intracellular LPS independent of TLR4. Science 341(6151): 12461249. doi: $10.1126 /$ science. 1240248

49. Devault A, Banuls AL (2008). The promastigote surface antigen gene family of the Leishmania parasite: differential evolution by positive selection and recombination. BMC Evol Biol 8: 292. doi: 10.1186/1471-2148-8-292

50. Shio MT, Christian JG, Jung JY, Chang KP, Olivier M (2015). PKC/ROS-Mediated NLRP3 Inflammasome Activation Is Attenuated by Leishmania Zinc-Metalloprotease during Infection. PLoS Negl Trop Dis 9(6): e0003868. doi: 10.1371/journal.pntd.0003868

51. Walle LV, Van Opdenbosch $N$, Jacques $P$, Fossoul $A$, Verheugen $E$, Vogel P, Beyaert R, Elewaut D, Kanneganti TD, van Loo G, Lamkanfi M 
(2014). Negative regulation of the NLRP3 inflammasome by A20 protects against arthritis. Nature 512(7512): 69-73. doi: $10.1038 /$ nature13322

52. Rossi M, Castiglioni P, Hartley MA, Eren RO, Prevel F, Desponds C, Utzschneider DT, Zehn D, Cusi MG, Kuhlmann FM, Beverley SM, Ronet $C$, Fasel N (2017). Type I interferons induced by endogenous or exogenous viral infections promote metastasis and relapse of leishmaniasis. Proc Natl Acad Sci U S A 114(19): 4987-4992. doi: 10.1073/pnas.1621447114

53. da Silva Santos C, Boaventura V, Cardoso CR, Tavares N, Lordelo MJ, Noronha A, Costa J, Borges VM, de Oliveira $\mathrm{Cl}$, Van Weyenbergh J, Barral A, Barral-Netto M, Brodskyn Cl (2014). CD8 Granzyme BMediated Tissue Injury versus CD4IFNgamma-Mediated Parasite Killing in Human Cutaneous Leishmaniasis. J Invest Dermatol. doi: 10.1038/jid.2014.230

54. Novais FO, Carvalho LP, Graff JW, Beiting DP, Ruthel G, Roos DS, Betts MR, Goldschmidt MH, Wilson ME, de Oliveira Cl, Scott P (2013). Cytotoxic $\mathrm{T}$ cells mediate pathology and metastasis in cutaneous leishmaniasis. PLoS Pathog 9(7): e1003504. doi: 10.1371/journal.ppat.1003504

55. Lye LF, Owens K, Shi H, Murta SM, Vieira AC, Turco SJ, Tschudi C, Ullu E, Beverley SM (2010). Retention and loss of RNA interference pathways in trypanosomatid protozoans. PLoS Pathog 6(10): e1001161. doi: 10.1371/journal.ppat.1001161

56. Michallet MC, Meylan E, Ermolaeva MA, Vazquez J, Rebsamen M, Curran J, Poeck H, Bscheider M, Hartmann G, Konig M, Kalinke U, Pasparakis M, Tschopp J (2008). TRADD protein is an essential component of the RIG-like helicase antiviral pathway. Immunity 28(5): 651661. doi: 10.1016/j.immuni.2008.03.013

57. Horai R, Asano M, Sudo K, Kanuka H, Suzuki M, Nishihara M, Takahashi $M$, Iwakura $Y$ (1998). Production of mice deficient in genes for interleukin (IL)-1alpha, IL-1beta, IL-1alpha/beta, and IL-1 receptor antagonist shows that IL-1beta is crucial in turpentine-induced fever development and glucocorticoid secretion. J Exp Med 187(9): 14631475. PMID: 9565638

58. Staehli F, Ludigs K, Heinz LX, Seguin-Estevez Q, Ferrero I, Braun M, Schroder K, Rebsamen M, Tardivel A, Mattmann C, MacDonald HR, Romero P, Reith W, Guarda G, Tschopp J (2012). NLRC5 deficiency selectively impairs MHC class I- dependent lymphocyte killing by cytotoxic $T$ cells. J Immunol 188(8): 3820-3828. doi: 10.4049/jimmunol.1102671 